\title{
Statistical Method to Evaluate the Relationship between Climatic Factors during the Development Periods of Flowering and Boll Formation and Cotton Production
}

\author{
Zakaria M Sawan* \\ Cotton Research Institute, Agricultural Research Center, Egypt
}

Submission: December 07, 2015; Published: December 29, 2015

*Corresponding author: Zakaria M Sawan, Cotton Research Institute, Agricultural Research Center, Ministry of Agriculture \& Land Reclamation, 9 Gamaa Street, 12619, Giza, Egypt, Email: zmsawan@hotmail.com

\begin{abstract}
This study investigated the relationship between climatic factors and production of flowers and bolls obtained during the development periods of the flowering and boll stage, and to determine the most representative period corresponding to the overall crop pattern. Evaporation, sunshine duration, relative humidity, surface soil temperature at $1800 \mathrm{~h}$, and maximum air temperature, are the important climatic factors that significantly affect flower and boll production. There was a negative correlation between flower and boll production and either evaporation or sunshine duration, while that correlation with minimum relative humidity was positive. Higher minimum relative humidity, short period of sunshine duration, and low temperatures enhanced flower and boll formation. It could be concluded that the fourth quarter period of the production stage is the most appropriate and usable production time to collect data for determining efficient prediction equations for cotton flower and boll production, and making valuable recommendations.
\end{abstract}

Keywords: Cotton flower and boll production; Evaporation; Relative humidity; Sunshine duration; Temperature.

\section{Introduction}

Cotton yield is a function of growth rates, flower production rates, and flower and boll retention during the fruiting period. Information on the relationship between climatic factors and the cotton plant's ability to produce and sustain flower buds, flowers, and bolls will allow one to model plant responses to conditions that frequently occur in the field and to predict developmental rate or the formation of these organs. Understanding the impacts of climatic factors on cotton production may help physiologists to determine the control mechanisms of boll retention in cotton. However, weather affects crop growth interactively, sometimes resulting in unexpected responses to prevailing conditions [1].

Climate affects crop growth interactively, sometimes resulting in unexpected responses to prevailing conditions. Many factors, such as length of the growing season, climate (including solar radiation, temperature, light, wind, rainfall, and dew), cultivar, availability of nutrients and soil moisture, pests and cultural practices affect cotton growth [2]. The balance between vegetative and reproductive development can be influenced by soil fertility, soil moisture, cloudy weather, spacing and perhaps other factors such as temperature and relative humidity [3]. Weather, soil, cultivars, and cultural practices affect crop growth interactively, sometimes resulting in plants responding in unexpected ways to their conditions [4].

Water is a primary factor controlling plant growth. Xiao et al. (2000) [3] stated that, when water was applied at 0.85, 0.70, 0.55 or 0.40 ET (evapotranspiration) to cotton plants grown in pots, there was a close relationship between plant development and water supply. The fruit-bearing branches, square and boll numbers and boll size were increased with increased water supply. Barbour and Farquhar (2000) [5] reported on greenhouse pot trials where cotton cv. CS50 plants were grown at 43 or $76 \%$ relative humidity (RH) and sprayed daily with abscisic acid (ABA) or distilled water. Plants grown at lower RH had higher transpiration rates, lower leaf temperatures and lower stomatal conductance. Plant biomass was also reduced at the lower RH. Within each RH environment, increasing $\mathrm{ABA}$ concentration generally reduced stomatal conductance, evaporation rates, superficial leaf density and plant biomass, and increased leaf temperature and specific leaf area.

Temperature is also a primary factor controlling rates of plant 
growth and development. Burke et al. (1988) [6] has defined the optimum temperature range for biochemical and metabolic activities of plants as the thermal kinetic window (TKW). Plant temperatures above or below the TKW result in stress that limits growth and yield. The TKW for cotton growth is 23.5 to $32^{\circ} \mathrm{C}$, with an optimum temperature of $28^{\circ} \mathrm{C}$. Biomass production is directly related to the amount of time that foliage temperature is within the TKW. Gutiérrez and López (2003) [7] studied the effects of heat on the yield of cotton in Andalucia, Spain, during 1991-98, and found that high temperatures were implicated in the reduction of unit production. There was a significant negative relationship between average production and number of days with temperatures greater than $40^{\circ} \mathrm{C}$ and the number of days with minimum temperatures greater than $20^{\circ} \mathrm{C}$. Schrader et al. (2004) [8] stated that high temperatures that plants are likely to experience inhibit photosynthesis. Wise et al. (2004) [9] indicated that restrictions to photosynthesis could limit plant growth at high temperature in a variety of ways. In addition to increasing photorespiration, high temperatures $\left(35-42^{\circ} \mathrm{C}\right)$ can cause direct injury to the photosynthetic apparatus. Both carbon metabolism and thylakoid reactions have been suggested as the primary site of injury at these temperatures. Species/cultivars that retain fruits at high temperatures would be more productive both in the present-day cotton production environments and even more in future warmer world [10].

Zhou et al. (2000) [11] indicated that light duration is the key meteorological factor influencing the wheat-cotton cropping pattern and position of the bolls, while temperature had an important function on upper (node 7 to 9) and top (node 10) bolls, especially for double cropping patterns with early maturing varieties. In Egypt, field studies relating cotton flower and boll production to climatic factors are lacking. Cotton productions of field-grown plants are less sensitive to climatic fluctuations than production of greenhouse or growth chamber plants. For this reason, studies of simulated climatic factors conducted in the greenhouse or growth chamber cannot be reliably applied to field conditions [1]. The objectives of this investigation was to study the relationship between climatic factors and production of flowers and bolls obtained during the development periods of the flowering and boll stage, and to determine the most representative period corresponding to the overall crop pattern [12]. This could result in formulating advanced predictions as for the effect of certain climatic conditions on production of Egyptian cotton. Minimizing the deleterious effects of the factors through utilizing proper cultural practices will lead to improved cotton yield [10].

\section{Data and Methods}

Two uniform field trials were conducted at the experimental farm of the Agricultural Research Center, Ministry of Agriculture, Giza, Egypt (30oN, 31o: 28'E at an altitude of $19 \mathrm{~m}$ ), using the cotton cultivar Giza 75 (Gossypium barbadense L.) in 2 successive seasons (I and II). The soil texture was a clay loam, with an alluvial substratum $(\mathrm{pH}=8.07,42.13 \%$ clay, $27.35 \%$ silt, $22.54 \%$ fine sand, $3.22 \%$ coarse sand, $2.94 \%$ calcium carbonate and $1.70 \%$ organic matter) [13].

In Egypt, there are no rain-fed areas for cultivating cotton. Water for the field trials was applied using surface irrigation. Total water consumed during each of two growing seasons supplied by surface irrigation was about $6,000-\mathrm{m}^{3} \mathrm{~h}-1$. The criteria used to determine amount of water applied to the crop depended on soil water status. Irrigation was applied when soil water content reached about $35 \%$ of field capacity $(0-60 \mathrm{~cm})$. In season I, the field was irrigated on 15 March (at planting), 8 April (first irrigation), 29 April, 17 May, 31 May, 14 June, 1 July, 16 July, and 12 August. In season II, the field was irrigated on 23 March (planting date), 20 April (first irrigation), 8 May, 22 May, 1 June, 18 June, 3 July, 20 July, 7 August and 28 August. Techniques normally used for growing cotton in Egypt were followed. Each experimental plot contained 13 to 15 ridges to facilitate proper surface irrigation. Ridge width was $60 \mathrm{~cm}$ and length was $4 \mathrm{~m}$. Seeds were sown on 15 and 23 March in seasons I and II, respectively, in hills 20 $\mathrm{cm}$ apart on one side of the ridge. Seedlings were thinned to 2 plants per hill 6 weeks after planting, resulting in a plant density of about 166,000 plants ha-1. Phosphorus fertilizer was applied at a rate of $54 \mathrm{~kg}$ P205 ha-1 as calcium super phosphate during land preparation. Potassium fertilizer was applied at a rate of 57 $\mathrm{kg} \mathrm{K2O} \mathrm{ha-1} \mathrm{as} \mathrm{potassium} \mathrm{sulfate} \mathrm{before} \mathrm{the} \mathrm{first} \mathrm{irrigation} \mathrm{(as}$ a concentrated band close to the seed ridge). Nitrogen fertilizer was applied at a rate of $144 \mathrm{~kg} \mathrm{~N}$ ha-1 as ammonium nitrate in two equal doses: the first was applied after thinning just before the second irrigation and the second was applied before the third irrigation. Rates of phosphorus, potassium, and nitrogen fertilizer were the same in both seasons. These amounts were determined based on the use of soil tests [13].

After thinning, 261 and 358 plants were randomly selected (precaution of border effect was taken into consideration by discarding the cotton plants in the first and last two hills of each ridge) from 9 and 11 inner ridges of the plot in seasons I, and II respectively. Pest control management was carried out on an-asneeded basis, according to the local practices performed at the experimental [13]. Flowers on all selected plants were tagged in order to count and record the number of open flowers, and set bolls on a daily basis. The flowering season commenced on the date of the first flower appearance and continued until the end of flowering season (31 August). The period of whole September (30 days) until the 20th of October (harvest date) allowed a minimum of 50 days to develop mature bolls. In season I, the flowering period extended from 17 June to 31 August, whereas in season II, the flowering period was from 21 June to 31 August. Flowers produced after 31 August were not expected to form sound harvestable bolls, and therefore were not taken into account [13].

For statistical analysis, the following data of the dependent variables were collected: number of tagged flowers separately 
counted each day on all selected plants (Y1), number of retained bolls obtained from the total daily tagged flowers on all selected plants at harvest (Y2), and (Y3) percentage of boll retention ([number of retained bolls obtained from the total number of daily tagged flowers in all selected plants at harvest]/[daily number of tagged flowers on each day in all selected plants] $\mathrm{x}$ 100). As a rule, observations were recorded when the number of flowers on a given day was at least 5 flowers found in a population of 100 plants and this continued for at least five consecutive days. This rule omitted eight observations in the first season and ten observations in the second season. The number of observations (n) was 68 (23 June through 29 August) and 62 (29 June through 29 August) for the two seasons, respectively. Variables of the soil moisture status considered were, the day prior to irrigation, the day of irrigation, and the first and second days after the day of irrigation [13].

The climatic factors (independent variables) considered were daily data of: maximum air temperature $\left({ }^{\circ} \mathrm{C}, \mathrm{X} 1\right)$; minimum air temperature $\left({ }^{\circ} \mathrm{C}, \mathrm{X} 2\right)$; maximum-minimum air temperature (diurnal temperature range) $\left({ }^{\circ} \mathrm{C}, \mathrm{X} 3\right)$; evaporation (expressed as Piche evaporation) ( $\mathrm{mm}$ day-1, X4); surface soil temperature, grass temperature or green cover temperature at $0600 \mathrm{~h}\left({ }^{\circ} \mathrm{C}, \mathrm{X} 5\right)$ and $1800 \mathrm{~h}\left({ }^{\circ} \mathrm{C}, \mathrm{X} 6\right)$; sunshine duration (h day-1, X7); maximum relative humidity $(\mathrm{maxRH})(\%, \mathrm{X} 8)$, minimum relative humidity $(\mathrm{minRH})(\%, \mathrm{X})$ and wind speed (m s-1, X10) in season II only. The source of the climatic data was the Agricultural Meteorological Station of the Agricultural Research Station, Agricultural Research Center, Giza, Egypt. No rainfall occurred during the two growing seasons [14].
Statistical analysis was conducted using the procedures outlined in the general linear models (GLM, SAS Institute, Inc. 1985). Daily data of the dependent variables (flowers produced and bolls retained) were regressed as linear functions of the independent variables. Simple correlation between the initial group of independent variables and corresponding dependent variables were calculated for each season and for combined data of the two seasons. The significance of the simple correlation at a probability level not exceeding of $\mathrm{P}<0.15$ was tested to determine the important factors affecting the dependent variables. The 0.15 level for significance was used according to Cady and Allen (1972) [15]. Multiple linear regression equations (using stepwise method) comprising selected predictive variables were computed for the determined interval and coefficients of multiple determinations $\left(R^{2}\right)$ were calculated to measure the efficiency of the regression models in explaining the variation in data. Correlation and regression analyses were computed according to [16].

\section{Results and Discussion}

Daily number of flowers and number of bolls per plant that survived to maturity (dependent variables) during the production stage of the two growing seasons are graphically illustrated in Figures 1 and 2 [12]. Observations used in the statistical analysis were obtained during the flowering and boll stage (60 days for each season), which represent the entire production stage. The entire production stage was divided into four equivalent quarter's periods (15 days each) and used for correlation and regression analyses.

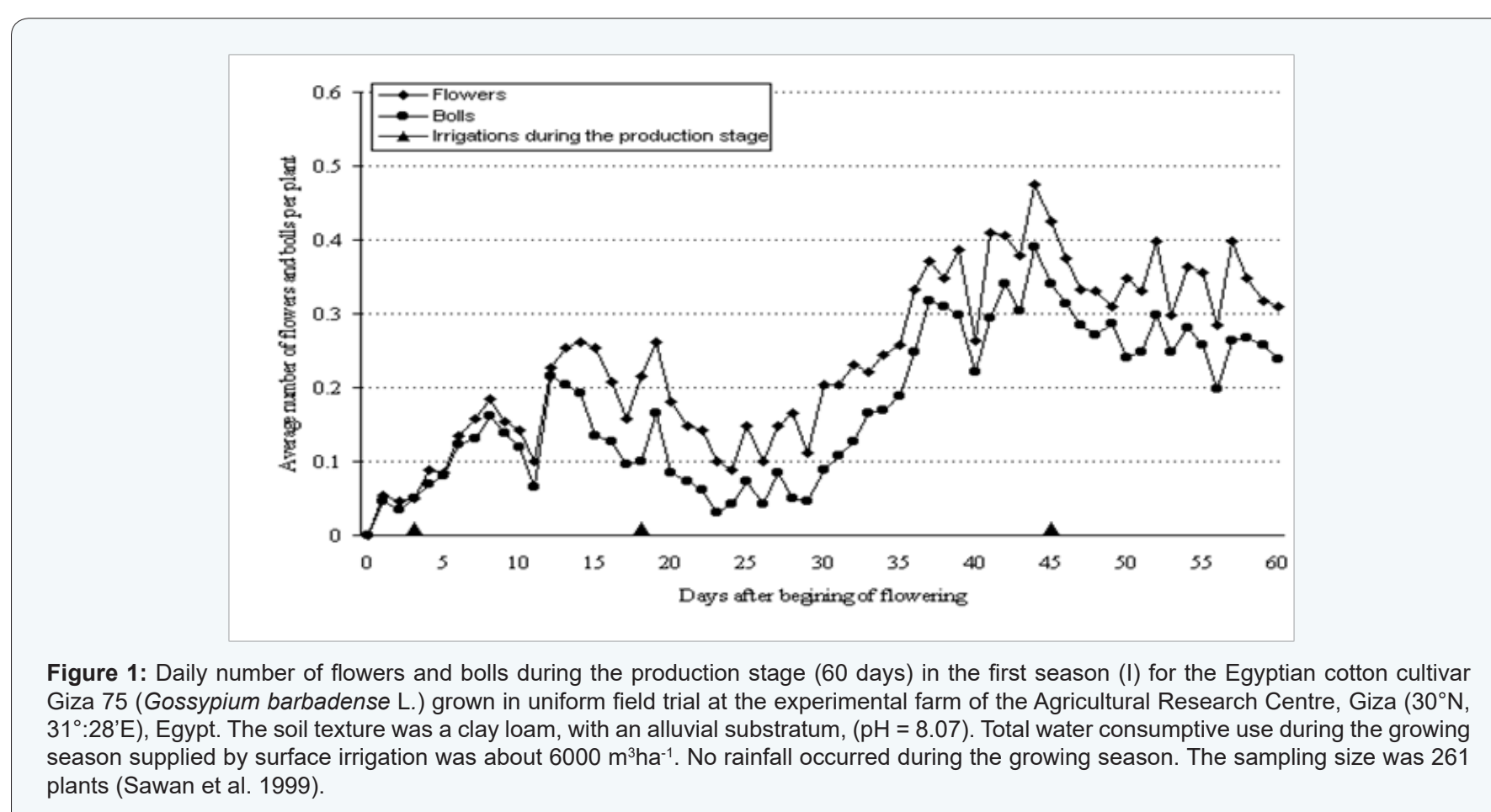




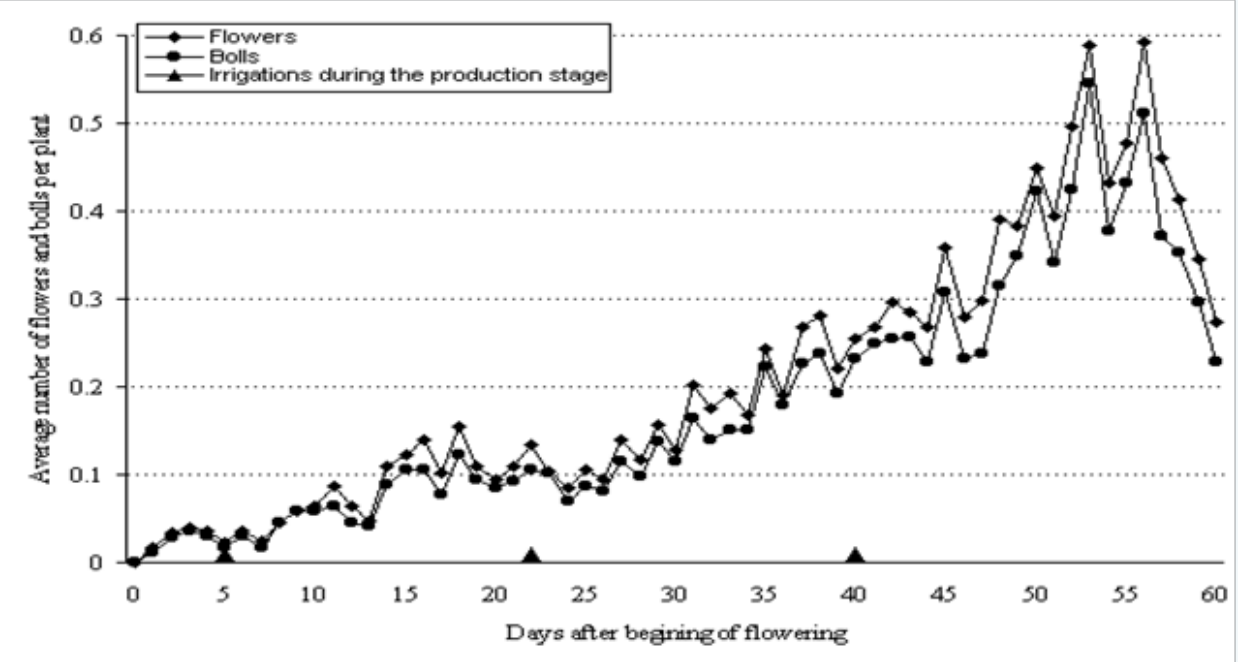

Figure 2: Daily number of flowers and bolls during the production stage (60 days) in the second season (II) for the Egyptian cotton cultivar Giza 75 (Gossypium barbadense L.) grown in uniform field trial at the experimental farm of the Agricultural Research Centre, Giza $\left(30^{\circ} \mathrm{N}\right.$, $\left.31^{\circ}: 28^{\prime} \mathrm{E}\right)$, Egypt. The soil texture was a clay loam, with an alluvial substratum, $(\mathrm{pH}=8.07)$. Total water consumptive use during the growing season supplied by surface irrigation was about $6000 \mathrm{~m}^{3} \mathrm{~h}^{\mathrm{a}-1}$. No rainfall occurred during the growing season. The sampling size was 358 plants (Sawan et al. 1999).

Independent variables, their range and mean values for the two seasons and during the periods of flower and boll production are listed in (Table 1) [12]. Both flower number and boll production show the higher value in the third and fourth quarters of production stage, accounting for about $70 \%$ of total production during the first season and about $80 \%$ of the total in the second season. Linear correlation between the climatic factors and the studied characteristics, i.e. flower, boll production and boll retention ratio, were calculated based on quarters of the production stage for each season. Significant relationships $(<$ 0.15) are shown in Tables 2 and 3 [12]. Examining these tables, it is clear that the fourth quarter of production stage consistently exhibited the highest $\mathrm{R}^{2}$ values regardless of the second quarter for boll retention ratio; however, less data pairs were used $(n=30$ for combined data of the fourth quarter " $n=15$ for each quarter of each season") to calculate the relations.

Table 1. Range and mean value of the independent variables (climatic factors) during the four periods of flower and boll production stage. (Sawan et al. 1999).

\begin{tabular}{|c|c|c|c|c|c|c|c|c|}
\hline \multirow{2}{*}{ Climatic factors } & \multicolumn{2}{|c|}{ First priod } & \multicolumn{2}{|c|}{ Second period } & \multicolumn{2}{|c|}{ Third period } & \multicolumn{2}{|c|}{ Fourth period } \\
\hline & Range & Mean & Range & Mean & Range & Mean & Range & Mean \\
\hline \multicolumn{9}{|c|}{ First season } \\
\hline Max Temp ${ }^{\circ} \mathrm{C}, \quad\left(\mathrm{X}_{1}\right)$ & $31.0-37.3$ & 33.7 & $33.0-37.3$ & 34.7 & $32.4-37.2$ & 34.5 & $32.0-38.4$ & 33.8 \\
\hline Min Temp ${ }^{\circ} \mathrm{C}$ & $18.6-23.5$ & 21.4 & $20.6-23.5$ & 22.3 & $18.9-24.4$ & 21.6 & $19.6-23.8$ & 21.8 \\
\hline Max-Min ${ }^{\circ} \mathrm{C}, \quad\left(\mathrm{X}_{3}\right)$ & $9.4-14.8$ & 12.3 & $9.8-15.6$ & 12.4 & $9.7-18.3$ & 12.9 & $9.5-14.6$ & 12.0 \\
\hline Evapor. $\mathrm{mm} / \mathrm{d}, \quad\left(\mathrm{X}_{4}\right)$ & $10.2-15.2$ & 11.7 & $8.0-13.2$ & $` 10.1$ & $7.6-11.2$ & 9.1 & $7.7-11.1$ & 9.2 \\
\hline $0600 \mathrm{~h} \mathrm{Temp.}{ }^{\circ} \mathrm{C}, \quad\left(\mathrm{X}_{5}\right)$ & $14.2-19.9$ & 16.8 & $15.8-21.5$ & 18.9 & $13.9-21.1$ & 17.4 & $15.4-20.8$ & 18.0 \\
\hline $1800 \mathrm{~h} \mathrm{Temp.}{ }^{\circ} \mathrm{C}, \quad\left(\mathrm{X}_{6}\right)$ & $22.0-25,2$ & 23.8 & $22.2-27.0$ & 24.2 & $19.6-25.6$ & 24.1 & $21.8-26.0$ & 23.9 \\
\hline Sunshine $h / d, \quad\left(X_{7}\right)$ & $11.4-12.9$ & 12.4 & $10.4-12.4$ & 11.5 & $10.5-12.4$ & 11.6 & $9.9-12.2$ & 11.4 \\
\hline Max Hum \%, & $62-88$ & 80.7 & $84-94$ & 88.4 & $85-96$ & 89.9 & $76-96$ & 87.4 \\
\hline Min Hum \%, $\quad\left(X_{9}\right)$ & $21-37$ & 28.2 & $22-43$ & 31.4 & $17-42$ & 29.9 & $24-45$ & 34.0 \\
\hline
\end{tabular}




\section{International Journal of Environmental Sciences \& Natural Resources}

\begin{tabular}{|c|c|c|c|c|c|c|c|c|}
\hline \multicolumn{9}{|c|}{ Second Season } \\
\hline Max Temp ${ }^{\circ} \mathrm{C}, \quad\left(\mathrm{X}_{1}\right)$ & $31.4-38.8$ & 35.5 & $31.4-35.5$ & 33.4 & $32.6-37.9$ & 34.4 & $30.6-34.6$ & 32.8 \\
\hline Min Temp ${ }^{\circ} \mathrm{C}, \quad\left(\mathrm{X}_{2}\right)$ & $20.1-23.4$ & 21.3 & $19.6-23.1$ & 21.7 & $18.4-24.3$ & 22.3 & $18.6-23.9$ & 21.7 \\
\hline Max-Min ${ }^{\circ} \mathrm{C}, \quad\left(\mathrm{X}_{3}\right)$ & $9.4-17.6$ & 14.2 & $10.1-15.0$ & 11.7 & $9.6-17.0$ & 12.1 & $8.5-12.6$ & 11.0 \\
\hline Evapor. mm/d, $\quad\left(X_{4}\right)$ & $5.9-9.8$ & 7.5 & $5.0-7.0$ & 6.0 & $4.3-7.1$ & 5.6 & & \\
\hline $0600 \mathrm{~h}$ Temp. ${ }^{\circ} \mathrm{C}, \quad\left(\mathrm{X}_{5}\right)$ & $15.5-20.4$ & 17.5 & $15.2-21.4$ & 18.4 & $12.9-22.4$ & 18.7 & $13.3-21.0$ & 17.5 \\
\hline $1800 \mathrm{~h} \mathrm{Temp.}{ }^{\circ} \mathrm{C}, \quad\left(\mathrm{X}_{6}\right)$ & $22.8-26.5$ & 24.4 & $22.2-26.5$ & 24.2 & $22.9-27.4$ & 24.4 & $20.6-25.8$ & 23.6 \\
\hline Sunshine $\mathrm{h} / \mathrm{d}, \quad\left(\mathrm{X}_{7}\right)$ & $11.2-13.0$ & 12.4 & $10.9-12.6$ & 11.9 & $10.6-12.4$ & 11.6 & $10.3-12.3$ & 11.5 \\
\hline Max-Hum \%, $\quad\left(X_{8}\right)$ & $62-83$ & 71.7 & $51-82$ & 72.8 & $59-81$ & 74.7 & $64-84$ & 73.3 \\
\hline Min Hum \%, $\quad\left(X_{9}\right)$ & $23-44$ & 33.1 & $32-50$ & 41.3 & $29-51$ & 39.9 & $37-52$ & 44.7 \\
\hline Windspeed $\mathrm{m} / \mathrm{s}, \quad\left(\mathrm{X}_{10}\right)$ & $2.8-6.8$ & 5.1 & $3.4-6.6$ & 4.5 & $2.2-7.8$ & 4.4 & & \\
\hline
\end{tabular}

Table 2. Significant simple correlation values between the climatic factors and flower, boll production and boll retention ratio due to quarters of production stage.

n.s.: Means simple correlation coefficient is not significant at the 0.15 alpha level of significance.

* : Significant at $1 \%$ probability level, ${ }^{*}$ Significant at $5 \%$ probability level.

${ }^{++}$: Significant at $10 \%$ probability level, + Significant at $15 \%$ probability level.

$\mathrm{n}$ : Number of data pairs used in calculation.

Wind speed did not show significant effect upon the studied production variables. (Sawan et al. 1999)

\begin{tabular}{|c|c|c|c|c|c|c|c|c|c|c|c|c|}
\hline \multirow{2}{*}{ Climatic factors } & \multicolumn{4}{|c|}{ Flower } & \multicolumn{4}{|c|}{ Boll } & \multicolumn{4}{|c|}{ Ratio:Bolls/Flowers (100) } \\
\hline & $1^{\text {st }}$ & $2^{\text {nd }}$ & $3^{\text {rd }}$ & $4^{\text {th }}$ & $1^{\text {st }}$ & $2^{\text {nd }}$ & $3^{\text {rd }}$ & $4^{\text {th }}$ & $1^{\text {st }}$ & $2^{\text {nd }}$ & $3^{\text {rd }}$ & $4^{\text {th }}$ \\
\hline \multicolumn{13}{|c|}{ First season ( $n$ by quarter $=15$ ) } \\
\hline $\operatorname{MaxTemp}{ }^{\circ} \mathrm{C},\left(\mathrm{X}_{1}\right)$ & n.s. & n.s. & n.s. & n.s. & n.s. & n.s. & n.s. & n.s. & n.s. & n.s. & n.s. & n.s.. \\
\hline Min Temp ${ }^{\circ} \mathrm{C},\left(\mathrm{X}_{2}\right)$ & $0.516^{*}$ & $0.607^{*}$ & n.s. & n.s. & $0.561^{*}$ & $0.638^{* *}$ & n.s. & n.s. & n.s. & $0.680^{* *}$ & n.s. & n.s. \\
\hline $\operatorname{Max}-\operatorname{Min}{ }^{\circ} \mathrm{C},\left(\mathrm{X}_{3}\right)$ & n.s. & n.s. & $0.538^{*}$ & n.s. & n.s. & n.s. & $0.494^{*}$ & n.s. & $0.515^{*}$ & n.s. & n.s. & n.s. \\
\hline Evapor. mm/d, $\left(\mathrm{X}_{4}\right)$ & $0.512^{*}$ & $0-.598^{*}$ & n.s. & $0.424^{++}$ & $0.397^{+}$ & $-0.500^{*}$ & $-.0321^{+}$ & n.s. & n.s. & $-0.387^{+}$ & $-0.287^{+}$ & n.s. \\
\hline 0600 h Temp. ${ }^{\circ} \mathrm{C},\left(\mathrm{X}_{5}\right)$ & $-0.352^{+}$ & $0.534^{*}$ & $-0.358^{+}$ & $0.301^{+}$ & $0.402^{+}$ & $0.516^{*}$ & $-0.441^{++}$ & n.s. & n.s. & $0.440^{++}$ & n.s. & $-.292^{+}$ \\
\hline $1800 \mathrm{~h} \mathrm{Temp} .{ }^{\circ} \mathrm{C},\left(\mathrm{X}_{6}\right)$ & n.s. & n.s. & n.s. & n.s. & n.s. & n.s. & n.s. & n.s. & n.s. & n.s. & n.s. & n.s. \\
\hline Sunshine $\mathrm{h} / \mathrm{d},\left(\mathrm{X}_{7}\right)$ & n.s. & n.s. & $0.346^{+}$ & n.s. & n.s. & n.s. & n.s. & $0.430^{++}$ & n.s. & n.s. & n.s. & $0.480^{*}$ \\
\hline Max Hum \%, $\left(X_{8}\right)$ & $-0.316^{+}$ & $-0.260^{+}$ & $0.461^{++}$ & $0.283^{+}$ & n.s. & n.s. & $0.410^{++}$ & n.s. & $.389^{+}$ & n.s. & n.s. & $-0.322^{+}$ \\
\hline Min Hum \%, $\left(X_{9}\right)$ & n.s. & $0.309^{+}$ & $-0.436^{++}$ & n.s. & n.s. & $0.436^{++}$ & $-0.316^{++}$ & n.s. & $-0.473^{++}$ & $0.527^{*}$ & n.s. & n.s. \\
\hline \multicolumn{13}{|c|}{ Second season ( $n$ by quarter $=15$ ) } \\
\hline $\operatorname{MaxTemp}{ }^{\circ} \mathrm{C},\left(\mathrm{X}_{1}\right)$ & n.s. & n.s. & n.s. & $-0.730^{* *}$ & n.s. & n.s. & n.s. & $-0.654^{* *}$ & n.s. & n.s. & $0.407^{++}$ & n.s. \\
\hline $\operatorname{Min}$ Temp ${ }^{\circ} \mathrm{C},\left(\mathrm{X}_{2}\right)$ & n.s. & n.s. & n.s. & $-0.451^{++}$ & n.s. & n.s. & n.s. & $-0.343^{+}$ & n.s. & n.s. & n.s. & n.s. \\
\hline $\operatorname{Max}-\operatorname{Min}{ }^{\circ} \mathrm{C},\left(\mathrm{X}_{3}\right)$ & n.s. & n.s. & $0.598^{*}$ & n.s. & n.s. & n.s. & $0.536^{*}$ & n.s. & $0.456^{++}$ & $-0.416^{++}$ & n.s. & n.s. \\
\hline Evapor. mm/d, $\left(X_{4}\right)$ & n.s. & n.s. & $0.640^{* *}$ & n.s. & n.s. & n.s. & $0.580^{*}$ & n.s. & n.s. & $-0.318^{+}$ & n.s. & n.s. \\
\hline $0600 \mathrm{~h} \mathrm{Temp} .{ }^{\circ} \mathrm{C},\left(\mathrm{X}_{5}\right)$ & $-0.397^{+}$ & $-0.301^{+}$ & $-0.407^{++}$ & $-0.506^{*}$ & $-0.380^{+}$ & $-0.323^{+}$ & $-0.332^{+}$ & $-0.426^{++}$ & n.s. & n.s. & $0.283^{+}$ & n.s. \\
\hline $1800 \mathrm{~h} \mathrm{Temp} .{ }^{\circ} \mathrm{C},\left(\mathrm{X}_{6}\right)$ & n.s. & $-.0440^{++}$ & n.s. & $-0.656^{* *}$ & n.s. & $-0.410^{++}$ & n.s. & $-0.582^{*}$ & $-.0626^{* *}$ & n.s. & n.s. & n.s. \\
\hline Sunshine $\mathrm{h} / \mathrm{d},\left(\mathrm{X}_{7}\right)$ & $0.362^{+}$ & n.s. & n.s. & n.s. & $0.340^{+}$ & $0.308^{+}$ & $.354^{+}$ & n.s. & n.s. & $0.409^{++}$ & n.s. & n.s. \\
\hline Max Hum \%, $\left(X_{8}\right)$ & $-0.523^{*}$ & $0.424^{++}$ & $-0.587^{*}$ & n.s. & $-0530^{*}$ & $0.431^{++}$ & $-0.586^{*}$ & n.s. & n.s. & n.s. & n.s. & n.s. \\
\hline Min Hum \%, $\left(X_{q}\right)$ & n.s. & n.s. & $-0.585^{*}$ & $0.639^{* *}$ & n.s. & n.s. & $-0.517^{*}$ & $0.652^{* *}$ & n.s. & n.s. & n.s. & $0.420^{++}$ \\
\hline
\end{tabular}


Table 3: Significant simple correlation values between the climatic factors and flower, boll production, and boll retention ratio due to quarters periods of production stage for the combined data of the two seasons $(n=30)$.

n.s: Means simple correlation coefficient is not significant at the 0.15 alpha level of significance.

* Significant at $1 \%$ probability level, " Significant at $5 \%$ probability level.

${ }^{++}$Significant at $10 \%$ probability level, + Significant at $15 \%$ probability level.

$\mathrm{n}$ Number of data pairs used in calculation.

Wind speed did not show significant effect upon the studied production variables.

(Sawan et al. 1999)

\begin{tabular}{|c|c|c|c|c|c|c|c|c|c|c|c|c|}
\hline \multirow{2}{*}{ Climatic factors } & \multicolumn{4}{|c|}{ Flower } & \multicolumn{4}{|c|}{ Boll } & \multicolumn{4}{|c|}{ Ratio: Bolls/Flowers (100) } \\
\hline & $1^{\text {st }}$ & $2^{\text {nd }}$ & $3^{\text {rd }}$ & $4^{\text {th }}$ & $1^{\text {st }}$ & $2^{\text {nd }}$ & $3^{\text {rd }}$ & $4^{\text {th }}$ & $1^{\text {st }}$ & $2^{\text {nd }}$ & $3^{\text {rd }}$ & $4^{\text {th }}$ \\
\hline $\operatorname{MaxTemp}{ }^{\circ} \mathrm{C},\left(\mathrm{X}_{1}\right)$ & n.s. & n.s. & $0.29^{+}$ & $-0.48^{* *}$ & n.s. & n.s. & $0.38^{++}$ & $-0.47^{* *}$ & $0.27^{+}$ & n.s. & n.s. & n.s. \\
\hline Min Temp ${ }^{\circ} \mathrm{C},\left(\mathrm{X}_{2}\right)$ & n.s. & n.s. & $-0.35^{++}$ & n.s. & n.s. & n.s. & $-0.28^{+}$ & n.s. & n.s. & n.s. & n.s. & n.s. \\
\hline $\operatorname{Max}-\operatorname{Min}{ }^{\circ} \mathrm{C},\left(\mathrm{X}_{3}\right)$ & $-0.40^{*}$ & $-0.30^{+}$ & $0.59^{* *}$ & $-0.36^{++}$ & n.s. & $-0.48^{* *}$ & $0.52^{* *}$ & $-0.38^{++}$ & $-0.40^{*}$ & $-0.47^{* *}$ & n.s. & $-0.28^{+}$ \\
\hline Evapor. mm/d, $\left(\mathrm{X}_{4}\right)$ & $0.78^{* *}$ & n.s. & $0.32^{++}$ & $-0.67^{* *}$ & $0.67^{* *}$ & $-0.51^{* *}$ & n.s. & $-0.74^{* *}$ & n.s. & $-0.82^{* *}$ & $-0.49^{* *}$ & $-0.72^{*+}$ \\
\hline $0600 \mathrm{~h} \mathrm{Temp} .{ }^{\circ} \mathrm{C},\left(\mathrm{X}_{5}\right)$ & n.s. & $0.27^{+}$ & $-0.43^{*}$ & $-0.31^{+}$ & n.s. & n.s. & $-0.37^{++}$ & $-0.37^{++}$ & n.s. & n.s. & n.s. & n.s. \\
\hline $1800 \mathrm{~h} \mathrm{Temp} .{ }^{\circ} \mathrm{C},\left(\mathrm{X}_{6}\right)$ & n.s. & n.s. & n.s. & $-0.42^{*}$ & n.s. & n.s. & n.s. & $-0.37^{++}$ & n.s. & n.s. & n.s. & n.s. \\
\hline Sunshine $\mathrm{h} / \mathrm{d},\left(\mathrm{X}_{7}\right)$ & n.s. & n.s. & $0.38^{++}$ & n.s. & n.s. & n.s. & $0.32^{++}$ & n.s. & n.s. & $0.30^{+}$ & n.s. & $0.27^{+}$ \\
\hline Max Hum \%, $\left(X_{8}\right)$ & n.s. & n.s. & n.s. & $-0.64^{* *}$ & n.s. & n.s. & n.s. & $-0.71^{* *}$ & n.s. & $-0.60^{* *}$ & $-0.44^{*}$ & $-0.70^{* *}$ \\
\hline Min Hum \%, $\left(X_{9}\right)$ & n.s. & n.s. & $-0.54^{* *}$ & $0.69^{* *}$ & $-0.32^{++}$ & $0.42^{*}$ & $-0.37^{++}$ & $0.72^{* *}$ & n.s. & $0.72^{* *}$ & $0.40^{*}$ & $0.56^{* *}$ \\
\hline $\mathrm{R}^{2}$ & & 0.667 & 0.116 & 0.496 & 0.672 & 0.446 & 0.335 & 0.389 & 0.747 & 0.219 & 0.737 & 0.269 \\
\hline
\end{tabular}

Results obtained from the four quarters of the production period for each season separately and for the combined data of the two seasons, indicated that relationships varied markedly from one season to another. This may be due to the differences between the climatic factors in the two seasons; as illustrated by its ranges and means shown in Table 1 [12]. For example, maximum temperature and surface soil temperature at $1800 \mathrm{~h}$ did not show significant effects in the first season, while this trend differed in the second season.

Multiple linear regression equations obtained from data of the fourth quarter, for:

\section{Flower production}

$\mathrm{Y}=160.0+11.28 \mathrm{X} 1-4.45 \mathrm{X} 3-2.93 \mathrm{X} 4-5.05 \mathrm{X} 5-11.3 \mathrm{X} 6-$ $0.962 \times 8+2.36 \times 9$

$$
\text { And } \mathrm{R}^{2}=0.672^{* *}
$$

\section{Boll production}

$\mathrm{Y}=125.4+13.74 \mathrm{X} 1-6.76 \mathrm{X} 3-4.34 \mathrm{X} 4-6.59 \mathrm{X} 5-10.3 \mathrm{X} 6-$ $1.25 \times 8+2.16 \times 9$

With an $\mathrm{R}^{2}=0.747^{* *}$

\section{Boll retention ratio}

$\mathrm{Y}=81.93-0.272 \mathrm{X} 3-2.98 \mathrm{X} 4+3.80 \mathrm{X} 7-0.210 \mathrm{X} 8-0.153 \mathrm{X} 9$

And its $\mathrm{R}^{2}=0.615^{* *}$

\section{The equation obtained from data of the second quarter of production stage for boll retention ratio}

$Y=92.81-0.107 X 3-0.453 X 4+0.298 X 7-0.194 X 8+0.239 X 9$

And $\mathrm{R}^{2}=0.737^{* *}$

$\mathrm{R}^{2}$ values for these equations ranged from 0.615 to 0.747 . It could be concluded that these equations may predict flower and boll production and boll retention ratio from the fourth quarter period within about 62 to $75 \%$ of its actual means. Therefore, these equations seem to have practical value. Comparing Tables 3 and 4 [12], it can be seen that differences in $R^{2}$ between the fourth quarter and the entire production period of the two seasons for each of flower, boll production, and boll retention ratio were large $(0.266,0.325$, and 0.279 respectively). These differences are sufficiently large to make a wide gap under a typical field sampling situation. This could be due to the high percentage of flower and boll production for the fourth quarter. 
Table 4: Significant simple correlation values between the climatic factors and flower, boll ratio for combined data of the two seasons $(n=120)$. production and boll retention.

n.s. Means simple correlation coefficient is not significant at the 0.15 alpha level of significance.

"Significant at $1 \%$ probability level, " Significant at $5 \%$ probability level.

${ }^{++}$Significant at $10 \%$ probability level, + Significant at $15 \%$ probability level.

$\mathrm{n}$ Number of data pairs used in calculation.

Wind speed did not show significant effect upon the studied production variables.

(Sawan et al. 1999)

\begin{tabular}{|c|c|c|c|c|}
\hline Climatic factors & & Flower & Boll & Ratio \\
\hline MaxTemp ${ }^{\circ} \mathrm{C}$, & $\left(\mathrm{X}_{1}\right)$ & $-0.152++$ & n.s. & n.s. \\
\hline Min Temp ${ }^{\circ} \mathrm{C}$, & $\left(\mathrm{X}_{2}\right)$ & n.s. & n.s. & n.s. \\
\hline Max-Min ${ }^{\circ} \mathrm{C}$, & $\left(\mathrm{X}_{3}\right)$ & $-0.259^{* *}$ & $-0.254^{* *}$ & n.s. \\
\hline Evapor.mm/d, & $\left(\mathrm{X}_{4}\right)$ & $-0.327^{* *}$ & n.s. \\
\hline $0600 \mathrm{~h} \mathrm{Temp.}^{\circ} \mathrm{C}$, & $\left(\mathrm{X}_{5}\right)$ & n.s. & $-0.429^{* *}$ & n.s. \\
\hline $1800 \mathrm{~h} \mathrm{Temp.}{ }^{\circ} \mathrm{C}$ & $\left(\mathrm{X}_{6}\right)$ & $-0.204^{*}$ & $-0.180++$ & $-0.344^{* *}$. \\
\hline Sunshine $\mathrm{h} / \mathrm{d}$, & $\left(\mathrm{X}_{7}\right)$ & $-0.227^{*}$ & n.s & $0.335^{* *}$ \\
\hline Max Hum \%, & $\left(\mathrm{X}_{8}\right)$ & n.s. & $0.364^{* *}$ & $0.336^{*}$ \\
\hline Min Hum \%, & $\left(\mathrm{X}_{9}\right)$ & $0.303^{* *}$ & $0.422^{* *}$ & \\
\hline $\mathrm{R}^{2}$ & & $0.406^{* *}$ & & \\
\hline
\end{tabular}

Equations obtained from data of the fourth quarter explained more variations of flower, boll production and boll retention ratio. Evaporation, humidity and temperature are the principal climatic factors that govern cotton flower and boll production during the fourth quarter; since they were most strongly correlated with the dependent variables studied (Table 3) [12]. Evaporation, that seems to be the most important climatic factor, had negative significant relationship which means that high evaporation ratio reduces significantly flower and boll production. Maximum temperature, temperature-differentiates and maximum humidity also showed negative significant link with fruiting production, which indicates that these climatic variables have determinable effect upon Egyptian cotton fruiting production. Minimum humidity was positively high correlated in most quarter periods for flower, boll production and boll retention ratio. This means that an increase of this factor will increase both flower and boll production. Maximum temperature is sometime positively and sometime negatively linked to boll production (Table 3). These erratic correlations may be due to the variations in the values of this factor between the quarters of the production stages, as shown from its range and mean values (Table 1) [12].

Burke et al. (1990) [17] pointed out that the usefulness of the $27.5^{\circ} \mathrm{C}$ midpoint temperature of the TKW of cotton as a baseline temperature for a thermal stress index (TSI) was investigated in field trials on cotton cv. Paymaster 104. This biochemical baseline and measurements of foliage temperature were used to compare the TSI response with the cotton field performance. Foliage temperature was measured with hand-held $4^{\circ} \mathrm{C}$ field of view IR thermometer while plant biomass was measured by destructive harvesting. The biochemical based TSI and the physically based crop water stress index were highly correlated $\left(r^{2}=0.92\right)$ for cotton across a range of environmental conditions. Reddy et al. (1995) [18] in controlled environmental chambers pima cotton cv. S-6 produced less total biomass at $35.5^{\circ} \mathrm{C}$ than at $26.9^{\circ} \mathrm{C}$ and no bolls were produced at the higher temperature $40^{\circ} \mathrm{C}$. This confirms the results of this study as maximum temperature showed negative significant relationship with production variables in the fourth quarter period of the production stage. Zhen (1995) [19] found that the most important factors decreasing cotton yields in Huangchuan County, Henan, were low temperatures in spring, high temperatures and pressure during summer and the sudden fall in temperature at the beginning of autumn. Measures to increase yields included the use of the more suitable highoil cotton cultivars, which mature early, and choosing sowing dates and spacing so that the best use was made of the light and temperature resources available.

It may appear that the grower would have no control over boll shedding induced by high temperature, but this is not necessarily the case [20]. If he can irrigate, he can exert some control over temperature since transpiring plants have the ability to cool themselves by evaporation. The leaf and canopy temperatures of drought-stressed plants can exceed those of plants with adequate quantity of water by several degrees when air humidity is low [21]. The grower can partially overcome the adverse effects of high temperature on net photosynthesis by spacing plants to adequately expose the leaves. Irrigation may also increase photosynthesis by preventing stomata closure during the day. Adequate fertilization is necessary for maximum rates of photosynthesis. Finally, cultivars appear to differ in their heat tolerance [22]. Therefore, the grower can minimize boll abscission where high temperatures occur by selecting a heat-tolerant cultivar, planting date management, applying an 
adequate fertilizer, planting or thinning for optimal plant spacing, and irrigating as needed to prevent drought stress.

\section{Conclusions}

Evaporation, sunshine duration, relative humidity, surface soil temperature at $1800 \mathrm{~h}$, and maximum temperature, were the most significant climatic factors affecting flower and boll production of Egyptian cotton. Also, it could be concluded that the fourth quarter period of the production stage (Sawan et al. 1999) [23] is the most appropriate and usable production time to collect data for determining efficient prediction equations for cotton flower and boll production in Egypt, and making valuable recommendations. The negative correlation between each of evaporation and sunshine duration with flower and boll formation along with the positive correlation between minimum relative humidity value and flower and boll production, indicate that low evaporation rate, short period of sunshine duration and high value of minimum humidity would enhance flower and boll formation. Temperature appeared to be less important in the reproduction growth stage of cotton in Egypt than evaporation (water stress), sunshine duration and minimum humidity. These findings concur with those of other researchers except for the importance of temperature [24]. A possible reason for that contradiction is that the effects of evaporation rate and relative humidity were not taken into consideration in the research studies conducted by other researchers in other countries. The matter of fact is that temperature and evaporation are closely related to each other to such an extent that the higher evaporation rate could possibly mask the effect of temperature. Water stress is in fact the main player and other authors have suggested means for overcoming its adverse effect which could be utilized in the Egyptian cotton. It must be kept in mind that although the reliable prediction of the effects of the aforementioned climatic factors could lead to higher yields of cotton, yet only $50 \%$ of the variation in yield could be statistically explained by these factors and hence consideration should also be given to the management practices presently in use.

\section{References}

1. Sawan ZM, Hanna LI, Gad El Karim GhA, McCuistions WL (2002) Relationships between climatic factors and flower and boll production in Egyptian cotton (Gossypium barbadense). Journal of Arid Environment 52(4): 499-516.

2. El-Zik KM (1980) The cotton plant - its growth and development. Western Cotton Prod. Conf. Summary Proc., Fresno, CA, pp. 18-21.

3. Xiao J-F, Liu Z-G, Yu X-G, Zhang J-Y, Duan A-W (2000) Effects of different water application on lint yield and fiber quality of cotton under drip irrigation. Acta Gossypii Sinica 12(4): 194-197.

4. Sawan ZM (2013) Studying the relationship between climatic factors and cotton production by different applied methods. Journal of Stress Physiology \& Biochemistry 9(4): 251-278.

5. Barbour MM, Farquhar GD (2000) Relative humidity- and ABAinduced variation in carbon and oxygen isotope ratios of cotton leaves. Plant, Cell and Environment 23(5): 473-485.
6. Burke JJ, Mahan JR, Hatfield JL (1988) Crop specific thermal kinetic windows in relation to wheat and cotton biomass production. Agron Journal 80(4): 553-556.

7. Gutiérrez Mas JC, López M (2003) Heat, limitation of yields of cotton in Andalucia. Agricultura, Revista Agropecuaria 72(855): 690-692.

8. Schrader SM, Wise RR, Wacholtz WF, Ort DR, Sharkey TD (2004) Thylakoid membrane responses to moderately high leaf temperature in Pima Cotton. Plant, Cell and Environment 27(6): 725-735.

9. Wise RR, Olson AJ, Schrader SM, Sharkey TD (2004) Electron transport is the functional limitation of photosynthesis in field-grown Pima cotton plants at high temperature. Plant, Cell and Environment 27(6): 717-724.

10. Sawan ZM (2014a) Climatic factors: evaporation, sunshine, relative humidity, soil and air temperature and cotton production. Annual Research \& Review in Biology 4(18): 2835-2855.

11. Zhou Z-G, Meng Y-L, Shi Pei, Shen Y-Q Jia Z-K (2000) Study of the relationship between boll weight in wheat-cotton double cropping and meteorological factors at boll-forming stage. Acta Gossypii Sinica 12(3): 122-126.

12. Sawan ZM, Hanna LI, McCuistions WL (1999) Effect of climatic factors during the development periods of flowering and boll formation on the production of Egyptian cotton (Gossypium barbadense). Agronomie 19(6): 435-443.

13. Sawan ZM, Hanna LI, McCuistions WL, Foote RJ (2010) Egyptian cotton (Gossypium barbadense) flower and boll production as affected by climatic factors and soil moisture status. Theoretical and Applied Climatology 99(1): 217-227.

14. Sawan ZM, Hanna LI, McCuistions WL (2005) Response of flower and boll development to climatic factors before and after anthesis in Egyptian cotton. Climate Research 97(3): 553-591.

15. Cady FB, Allen DM (1972) Combining experiments to predict future yield data. Agron Journal 64(2): 211-214.

16. Draper NR, Smith H (1966) Applied Regression Analysis. John Wiley \& Sons Ltd., New York, NY. 407 pp . 736.

17. Burke JJ, Hatfield JL, Wanjura DF (1990) A thermal stress index for cotton. Agronomy Journal 82(3): 526-530.

18. Reddy KR, Hodges HF, McKinion JM (1995) Carbon dioxide and temperature effects on pima cotton growth. Agriculture Ecosystems \& Environment 54(1-2): 17-29.

19. Zhen J-Z (1995) The causes of low cotton production in Huanghchuan County and measures to increase production. Henan Nongye Kexue No. 2: 5-6.

20. Guinn G (1982) Causes of square and boll shedding in cotton. USDA Tech. Bull. 1672. USDA, Washington, DC.

21. Ehrler WL (1973) Cotton leaf temperatures as related to soil water depletion and meteorological factors. Agronomy Journal 65(3): 404409.

22. Fisher WD (1975) Heat induced sterility in Upland cotton. Proc $27^{\text {th }}$ Cotton Improvement Conference. 85.

23. Sawan ZM (2014b) Nature relation between climatic variables and cotton production. Journal of Stress Physiology \& Biochemistry 10(3): 197-217.

24. SAS Institute, Inc (1985) SAS User's Guide: Statistics. $5^{\text {th }}$ ed. SAS Institute, Inc., Cary, NC. pp. 433-506. 